\title{
3 Research Suare

\section{Willingness of the UK public to volunteer for testing in relation to the COVID-19 pandemic}

\author{
Tushna Vandrevala ( $\nabla$ t.vandrevala@kingston.ac.uk) \\ Kingston University https://orcid.org/0000-0002-1140-8445 \\ Amy Montague \\ Kingston University \\ Philip Terry \\ Kingston University \\ Mark D. Fielder \\ Kingston University
}

\section{Research article}

Keywords: COVID-19, testing, risk perception

Posted Date: September 8th, 2020

DOI: https://doi.org/10.21203/rs.3.rs-65546/v1

License: (c) (7) This work is licensed under a Creative Commons Attribution 4.0 International License. Read Full License 


\section{Abstract}

Background: The World Health Organization declared the rapid spread of COVID-19 around the world to be a global public health emergency. The spread of the disease is influenced by people's willingness to adopt preventative public health behaviours, such as participation in testing programmes and risk perception can be an important determinant of engagement in such behaviours.

Methods: In this study, we present the first assessment of how the UK public $(\mathrm{N}=778)$ perceive the usefulness of testing for coronavirus and the factors that influence a person's willingness to test for coronavirus.

Results: None of the key demographic characteristics (age, gender, education, disability, vulnerability status, or professional expertise) were significantly related to the respondents' willingness to be tested for coronavirus. However, closely following the news media was positively related to willingness to be tested. Knowledge and perceptions about Coronavirus significantly predicted willingness to test, with three significantly contributing factors: worry about the health and social impacts to self and family; personal susceptibility; and concerns about the impacts of coronavirus on specific demographic groups. Views on testing for coronavirus predicted willingness to test, with the most influential factors being importance of testing by need; negative views about widespread testing and mistrust in doctor's advice about testing.

Conclusions: Implications for effective risk communication and localised public health approach to encouraging public to put themselves forward for testing are discussed. We strongly advocate for effective communications and localised intervention by public health authorities, using media outlets to ensure that members of the public get tested for SARs-CoV2 when required.

\section{Background}

In December 2019 a novel coronavirus emerged as a cause of a pneumonia in Hubei province of China with an apparent epicentre in the city of Wuhan. ${ }^{1}$ The new coronavirus (SARS-CoV-2) causes acute respiratory syndrome (COVID-19). The disease has subsequently spread globally and was declared a pandemic by the World Health Organization (WHO). Global infections reached 8,373,746 cases and 449,512 deaths as of 18th June $2020 .^{2}$ The disease symptoms were first fully described by Huang et al. ${ }^{3}$, a study of 41 patients which revealed the common, initial clinical features to be fever ( $98 \%$ ) and cough $76 \%$ ); $55 \%$ of patients also reported dyspnea. Most patients presented with lung opacity similar to that of ground glass following imaging. Other reports identified additional symptoms such as myalgia, fatigue and sore throat. ${ }^{4}$ These symptoms remain sentinel clinical markers for COVID-19 infection; more recently, anosmia and ageusia were also identified as notable symptoms. ${ }^{5,6}$, and the UK government consequently included them as part of the case description for COVID-19. ${ }^{7}$ Also noted were characteristics that appear to increase the risk of infection: men appear to be at greater risk than women to the infection, ${ }^{8}$ there is also mounting evidence that certain ethnic minority groups are at higher risk. Pareek and colleagues ${ }^{9}$ explored the possibility that ethnicity is linked to the acquisition, transmission and severity of COVID-19 infection. Other studies have further highlighted the increased risk to the Black, Asian and minority ethnic (BAME) community, both for amongst the general populations and for those working in healthcare. $8,11,12$ More work is needed to understand the factors contributing to this elevated risk. ${ }^{10}$ Another risk factor is age. ${ }^{8,12-14}$ it has been noted that death rates appear to increase following SARs-CoV2 in patients with an increased age. ${ }^{4}$ Patients below the age of 9 years have a death rate of circa $0.0016 \%$, but the mortality rate increases to around $7.8 \%$ in infected people aged 80 years or over. ${ }^{4,15}$ Around $20 \%$ of infected 
patients older than 80 years require hospitalisation, whereas patients below 30 years of age represent only around $1 \%$ of admissions (reported by Verity et al., ${ }^{4}$ and reviewed by Mahase, 2020. ${ }^{15}$ )

The pandemic response in many countries, including the UK, has been to "lock down" communities to prevent further spread of the virus. However, an extended lockdown is likely to cause economic hardship and other negative societal effects on the affected communities. ${ }^{18}$ The successful lifting of lockdown measures requires an effective and extensive testing regime. ${ }^{17}$ An approach based on testing and isolating has been extensively adopted in some countries with great effect. For example, South Korea saw dramatic falls in cases by implementing an extensive testing regime supported by a trace-and-quarantine program for the contacts of those testing positive. ${ }^{16}$

There are currently two main types of test in use, one is a molecular test that detects the RNA genome of the SARsCoV-2 virus using an RT-PCR test protocol. The other is serology-based, and tests for the presence of an immune response to the virus, indicating whether a person has had the virus previously. These tests are clearly extremely useful epidemiological tools, not only for understanding the extent of the outbreak, but also for estimating the prevalence of asymptomatic cases in the community. ${ }^{19}$ It has been claimed that RNA testing is important to the success of any lockdown exit strategy; however, the importance of identifying asymptomatic individuals is still unclear. ${ }^{20}$ Mass testing could be a tool to help bring the epidemic rapidly to an end: COVID-19 testing kits could be distributed widely via the GP network in the UK, whilst hard-to-reach groups might be accessed via charitable organisations; ${ }^{21}$ the testing could be carried out weekly, and those that test negative could return to 'normal' life whilst those who test positive can be treated (and their contacts quarantined). However, some might see this approach as too intrusive and authoritarian. Indeed, the WHO's standard containment approach of "find, test, treat, and isolate" was not the approach advocated in the UK. At the time of data collection, community-based case identifying, testing, and contact tracing were not common practice.

It is important to understand public perceptions of personal and societal risk factors during pandemics and how they can influence the public's willingness to cooperate and adopt health-protective behaviours during pandemics. ${ }^{22}$ However, compared to other risk domains, such as environmental risks far less is known about how the public perceives risks associated with emerging infectious diseases. ${ }^{23,24}$ The public's capacity to comply with recommendations during pandemics or other emergencies in influenced by a range of modifiable or non-modifiable factors, including their sociodemographic status; what they perceive to be their own susceptibility to infection ${ }^{21}$; whether they perceive the infection to be serious; whether they have the necessary confidence to make changes; and the perceived costs and benefits of actions. ${ }^{22,24}$ In order to develop effective public health messages it is therefore important to understand the public's perceptions of the threat posed by the pandemic and how they are likely to respond behaviourally. Accordingly, we carried out a cross sectional online survey of public beliefs about and attitudes towards coronavirus and testing for coronavirus, and examined how these perceptions influenced personal willingness to be tested for COVID-19. The primary aim of the current study was to identify factors that increase or decrease willingness to volunteer for testing.

\section{Methods}

\section{Participants}

The sample comprised 778 UK residents (181 males and 589 females, 8 other/prefer not to say); their ages ranged from 18 to $80 \mathrm{yrs}$ old, with the average age being $47 \mathrm{yrs}$. The sample was predominantly white (86\%), with remaining participants identifying as 'Black', 'Asian', 'Mixed' and 'other' ethnic groups (14\%). Full demographic details are given in Table 1. At the time of completing the survey, only 3.5\% of the sample had been tested for coronavirus. 
Table 1

Demographic characteristics of sample $(\mathrm{N}=778)$

\begin{tabular}{|c|c|c|}
\hline Variable & & \\
\hline \multirow[t]{2}{*}{ Gender } & Male & $181(23.5 \%)$ \\
\hline & Female & $589(76.5 \%)$ \\
\hline \multirow[t]{4}{*}{ Age (yrs) } & Under 45 & $324(41.6 \%)$ \\
\hline & $45-69$ & $406(52.2 \%)$ \\
\hline & 70 and above & $44(5.7 \%)$ \\
\hline & Missing & $4(0.5 \%)$ \\
\hline \multirow[t]{5}{*}{ Ethnicity } & White & $675(86.8)$ \\
\hline & Black & $9(1.2 \%)$ \\
\hline & Asian & $54(6.9 \%)$ \\
\hline & Mixed & $22(2.8 \%)$ \\
\hline & Other & $18(2.3 \%)$ \\
\hline \multirow[t]{7}{*}{ Highest educational Qualification } & Post-Graduate & $284(36.5 \%)$ \\
\hline & Graduate & $257(33 \%)$ \\
\hline & A-levels & $123(15.8 \%)$ \\
\hline & GCSE'S & $62(8 \%)$ \\
\hline & NVQ & $6(0.8 \%)$ \\
\hline & None & $20(2.6 \%)$ \\
\hline & Other & $26(3.3 \%)$ \\
\hline \multirow[t]{3}{*}{ Disability (hidden or visible) or long-term illness } & Yes & $145(18.6)$ \\
\hline & No & $632(81.2)$ \\
\hline & Missing & $1(0.1 \%)$ \\
\hline \multirow[t]{4}{*}{ Government-defined 'vulnerable group' } & Yes & $32(4.1 \%)$ \\
\hline & No & $731(94.0)$ \\
\hline & Not applicable & $14(1.8 \%)$ \\
\hline & Missing & $1(0.1 \%)$ \\
\hline \multirow[t]{2}{*}{ Tested for Coronavirus } & Yes & $27(3.5 \%)$ \\
\hline & No & $751(96.5)$ \\
\hline Professional Expertise & Health & $75(9.6 \%)$ \\
\hline
\end{tabular}




\begin{tabular}{|lll|}
\hline Variable & & \\
\hline & Social Care & $19(2.4 \%)$ \\
& Scientist & $99(12.7 \%)$ \\
& Key worker & $78(10 \%)$ \\
\hline Perceived level of scientific knowledge & Multiple & $68(8.7 \%)$ \\
\hline & None mentioned & $439(56.4 \%)$ \\
\hline & Advanced and above & $196(25.2 \%)$ \\
\hline & Average & $444(57.1 \%)$ \\
\hline & Poor and below & $137(17.6 \%)$ \\
\hline
\end{tabular}

\section{Materials}

Participants completed questionnaires that were developed specifically for this study (see additional file 1). These questionnaires addressed "Knowledge and perceptions about coronavirus" and "Views on testing for coronavirus". The respondents indicated their level of agreement with each statement on a 4-point Likert scale from 'strongly disagree' to 'strongly agree'. Based on the initial responses, factor analysis consolidated the variables into discrete, coherent subscales (see additional file 2 for further details). Scores from these scales were the primary variables in all subsequent analyses (see additional file 3 for breakdown of variables).

Part 1: Knowledge and Perceptions about Coronavirus included the following sub-scales:

Confidence that taking action is effective ( 4 items, $\mathrm{a}=.651)$ reflects a person's confidence in actions being effective in terms of protecting themselves and others from coronavirus. Perceived Severity and Threat ( 5 items, $\mathrm{a}=.793$ ) encompasses the participant's beliefs about the ability of coronavirus to cause severe health problems or to represent a serious threat to them or to others.

Personal Susceptibility ( 3 items, $a=.776$ ) denotes the extent to which participants perceived themselves to be at risk of coronavirus due to their health status or age.

Worry About Economic Implications (3 items, $a=.696$ ) reflects participant concerns about personal finances and the long-term impacts of the virus on their job prospects and the economy.

Impact of Coronavirus on Specific Demographic Groups (5 items, $\mathrm{a}=.686$ ) indicates the participant's perceptions about the particular impacts on coronavirus on people over the age of 70 years old, ethnic communities, and/or people with underlying health conditions.

Positive Impacts on Self and Society (2 items, $\mathrm{a}=.717$ ) encompasses beliefs that the virus has had a positive impact on the participant's life and will have a positive impact on society in the future.

Worry about the Health and Social Impacts on Self and Family (4 items, $a=.452$ ) indicates the extent to which the participant worries about contracting coronavirus and its likely impacts on self and family. 
Part 2: Views on Testing for Coronavirus included the following sub-scales:

Negative views about Widespread Testing (4 items, $\mathrm{a}=.847$ ) denotes whether widespread testing was considered by participants to be a waste of time and resources.

Importance of Testing "by Need" (5 items, $\mathrm{a}=$.814) indicates how important participants felt it was to prioritise testing for themselves if they show symptoms, or for vulnerable people or those who work with vulnerable people.

Testing considered as an Effective Protective Measure (4 items, $\mathrm{a}=.804$ ) reflects the extent to which participants believe that testing could protect them or others from being infected by the coronavirus.

Trust in Government approach to Testing (4 items, $\mathrm{a}=.795)$ indicates how much the participant trusts the government's COVID testing strategy.

Willingness to be tested (2 items, a .814) indicates the extent to which participants would consider getting tested for coronavirus.

Trust in Doctor's Advice about Testing (3 items, $\mathrm{a}=.576$ ) indicates whether participants trust their doctors to inform them if they needed to get tested.

Beliefs that Testing can indicate Immunity ( 2 items, $a=.554)$ indicates whether participants believe testing will tell them if they have immunity from coronavirus and whether they have had coronavirus previously.

Worries about Testing Outcome ( 2 items, $a=.556)$ reflects the participant's worries about the results of coronavirus testing, including being a future burden on their family.

\section{Procedure}

Participants were recruited via an online advertisement distributed through social media during the UK governmentmandated 'Coronavirus lockdown' period between April 26 and May 15, 2020. Participants aged 18 years and above were invited to take part in a study looking at attitudes towards Coronavirus and testing during the pandemic.

Participants could access a hyperlink in the advertisement which directed them to the anonymous online survey. The survey was presented via the Qualtrics platform. Study information and consent forms were presented before the first survey questions (demographic characteristics) and then the subsequent Coronavirus-related questions. It took participants approximately 15-20 minutes to complete; a debrief sheet was provided when they finished. The study received a favourable ethical opinion from the Kingston University Research Ethics Committee. All analyses were conducted using SPSS v26.

\section{Results}

None of the key demographic characteristics was significantly related to participant's willingness to be tested for coronavirus. Thus, there were no differences between men and women or between white and BAME respondents in terms of willingness to be tested (respectively: $t=0.236, d f=730, p>0.05 ; t=0.979, d f=735, p>0.05$ ). Similarly, age did not predict willingness to be tested (Spearman's rho $=0.052, p>0.05 ; N=734$ ). People who worked in professions that might confer relevant expertise (e.g. healthcare worker, social worker; $\mathrm{N}=413$ ) did not differ from those who worked in other fields $(N=319 ; t=0.436, d f=730, p>0.05)$; self-declared level of scientific knowledge was also unrelated to willingness to be tested (Spearman's rho $=0.008, \mathrm{~N}=737, \mathrm{p}>0.05$ ), and level of education also failed to predict willingness to be tested $(F[6,730]=1.24, p>0.05)$. However, the extent to which a person closely followed the 
news was modestly positively correlated significantly with willingness to test (Spearman's rho $=0.203, N=734, p<$ 0.005). Finally, neither self-declared vulnerable status nor disability status increased a person's willingness to be tested in comparison with non-vulnerable or non-disabled respondents (respectively: $t=0.518, d f=730, p>0.05 ; t=0.508, d f$ $=734, \mathrm{p}>0.05)$.

By multiple regression, the sub-scales from the Knowledge and Perceptions about Coronavirus section of the survey together significantly predicted willingness to test $(F[7,727]=8.68, p<0.001)$ but they explained only $7.7 \%$ of the variance in scores for willingness to be tested. Individual factors that significantly contributed to the regression model were "Worry about the Health and Social Impacts to Self and Family" (standardized beta $=0.12, p<0.005$ ), "Personal Susceptibility" (standardized beta $=-0.10, p<0.05$ ) and "Impacts of Coronavirus on Specific Demographic Groups" (standardized beta $=0.096, p<0.05)$. Factors that did not significantly contribute $(p>0.05)$ were "Perceived Severity and Threat", "Confidence that taking Action is Effective", "Worry about Economic Implications" and "Positive Impacts on Self and Society".

Looking at the second part of the survey (Views on Testing for Coronavirus), all of the factors together strongly predicted "Willingness to be Tested" $(F[7,724]=29.82, p<0.001)$ and explained $22.4 \%$ of the variance in scores. The most influential factors were "Importance of Testing "by Need"' (standardized beta = 0.27, p < 0.001); "Negative views about Widespread Testing" (standardized beta $=-0.233, \mathrm{p}<0.001$ ); "Trust in Doctor's Advice about Testing" (standardized beta $=-0.081, \mathrm{p}<0.05$ ). The negative result denote that participants were less likely to trust their doctor's advice about testing while making decisions regarding their willing to test. The non-significant factors in the model were "Testing Considered as an Effective Protective Measure"; "Trust in Government Approach to Testing"; "Beliefs that Testing can indicate Immunity" and "Worries about Testing Outcome” (for all, p >0.05).

\section{Discussion}

Testing for SARs-CoV2 enables infected people to be identified and isolated in order to reduce the spread of the virus. It can allow for contact tracing of potentially exposed individuals and yields data on localised rates of infections that can inform public health interventions. There is some evidence on how clinicians use and interpret SARs-CoV2 tests, ${ }^{26}$ but little is known about how the public perceive risk regarding coronavirus. ${ }^{23,24}$ There is no research on how a person's demographic characteristics or views and knowledge about testing might influence their willingness to be tested. In a situation such as the current pandemic it is of the utmost importance to understand public perception of risk, their knowledge about key healthcare interventions, and their willingness to engage in testing.

As lockdown eases and test and trace systems are seen by public health and government officials as a quick, vital and effective way to control the spread of the virus, the findings presented in this paper have potentially important implications. The current survey results indicate that willingness to be tested for coronavirus is not related to key demographic variables, such as age, gender, ethnicity, educational status or to professions that might confer relevant expertise (e.g. healthcare worker, social worker) or to self-declared level of scientific knowledge. Neither self-declared vulnerable status nor disability status influenced a person's willingness to be tested. Although willingness to be tested was unrelated to educational attainment, professional expertise or self-declared level of medical knowledge. Moreover, the findings clearly demonstrate that willingness to be tested is strongly influenced by their perceptions towards coronavirus. Interestingly, specifically the extent to which they worry about contracting coronavirus and its likely impacts on self and family. Also the extent to which they perceive themselves to be at risk of coronavirus due to their health status or age and their perceptions about the particular impacts on coronavirus on people over the age of 70 years old, ethnic communities and/or people with underlying health conditions. Despite this, perceptions of the overall severity and threat posed by the pandemic did not influence willingness to be tested; it seems that the threat 
(and likelihood of action) was viewed through the lens of personal circumstance. Willingness to be tested is therefore not a straightforward decision. Moreover, how people perceive the risk is not necessarily related to the actual risk; nevertheless, it is the perceived risk that influences protective behaviours. ${ }^{27}$ Uncertainty about the situation and perceived exaggeration have been associated with a reduced likelihood of implementing recommended protective behaviours during previous pandemics. ${ }^{21}$

Encouragingly, the findings of the current study suggest that the public's views on vulnerability predicted willingness to be tested. Increased willingness was associated with beliefs that it was important to prioritise testing "by need" for themselves (if symptomatic) or for vulnerable people, or for those working with vulnerable people. Test intention was negatively related to beliefs that widespread (indiscriminate) testing would be a waste of time and resources. Furthermore, the public were also less likely to report willingness to be tested if they trusted their doctors to advise them about the need for testing. Interestingly, our findings suggest that the extent to which a person closely followed the news were related to willingness to test. The influence of the media in contrast to mistrust in doctors to advise them about testing warrants further investigation. In contrast, the following did not predict intention to test: the extent to which the respondent felt that testing was an effective protective measure; their beliefs about testing providing immunity; their worries about testing outcomes; and their trust in the government's approach to testing. The latter outcome contrasts with previous research indicating that trust in government is related to risk perceptions. ${ }^{23}$

The current study covers a large cross-sectional sample of the adult population in the UK. Members of the public were excluded from the sample if they were unable to communicate in English and it is duly noted that this exclusion may have had an effect on the representation of some ethnic minority groups or communities. In addition, participation in the current study was on a voluntary basis. As a result, there is potential for the participants in this study to show a level of self-selection based upon their particular concern with regard to this pandemic.

\section{Conclusions}

The findings presented here advocate that public views on willingness to test were related to modifiable factors, such as risk perceptions to coronavirus and views on testing. In order to develop effective public health messages, interventions should be designed to address these specific public perceptions posed by the pandemic, which, in turn correspond to how people respond behaviourally. There is, therefore, a growing need to ensure that a public health approach towards case test and tracking, with the adequate support of public health teams who know their communities, the nature of the outbreak in their communities is employed to assist individuals and communities navigate some of the decisions they face regarding testing. Effective communications and localised intervention by public health authorities, using media outlets to disseminate information are of particular use in ensuring that members of the public get tested for SARs-CoV2 when required. Scally, ${ }^{28}$ advocates that plans for community contact tracing must be adequately resourced, decentralised, and led by local public health teams; Public Health England and the NHS must fully support these plans. A localised public health approach could specifically address the public's risk perception of the virus and testing and ensure than public messaging is reframed to address these issues.

\section{Abbreviations}

SARS-CoV-2: Severe Acute Respiratory Syndrome - Coronavirus 2; COVID-19: Coronavirus Disease 2019; WHO: World Health Organisation; BAME: Black, Asian and Minority Ethnic; RT-PCR: Real-Time Polymerase Chain Reaction; RNA: Ribonucleic Acid tests; GP: General Practitioner

\section{Declarations}




\section{Ethics approval and consent to participate}

This research was conducted in accordance with relevant guidelines, regulations and was approved by the Research Ethics Board of Kingston University. Written informed consent was obtained from all respondents before participation in this study.

\section{Consent for publication}

Not applicable

\section{Availably of data and materials}

The datasets used and analysed during the current study are available from the corresponding author on reasonable request

\section{Competing interests}

The authors declare that they have no competing interests

\section{Funding}

Not applicable

\section{Acknowledgments}

Not applicable

\section{Authors' contributors}

TV, PT, MDF conceived the idea for the current study. Together with AM, the study was developed, data collected, analysed and the paper written as a collective. All authors have read and approved the manuscript.

\section{References}

1. World Health Organisation. Novel coronavirus (2019-ncov) situation report - 1. 21 JANUARY 2020 [Internet]. 2020. Available from: https://www.who.int/docs/default-source/coronaviruse/situation-reports/20200121-sitrep1-2019-ncov.pdf?sfvrsn=20a99c10_4

2. COVID-19 Map [Internet]. Johns Hopkins Coronavirus Resource Center. 2020 [cited 17 July 2020]. Available from: https://coronavirus.jhu.edu/map.html

3. Huang C, Wang Y, Li X, Ren L, Zhao J, Hu Y et al. Clinical features of patients infected with 2019 novel coronavirus in Wuhan, China. 2020;395(10223):497-506.

4. Verity R, Okell L, Dorigatti I, Winskill P, Whittaker C, Imai N et al. Estimates of the severity of coronavirus disease 2019: a model-based analysis. Lancet Infect Dis. 2020;20(6):669-677.

5. Karimi-Galougahi M, Raad N, Mikaniki N. Anosmia and the Need for COVID-19 Screening during the Pandemic. Otolaryngol Head Neck Surg. 2020;163(1):96-97.

6. Gane S, Kelly C, Hopkins C. Isolated Sudden Onset Anosmia in COVID-19 Infection. A Novel Syndrome?. J Rhinol. 2020;58(3):299-301. 
7. Department of Health and Social Care. Statement from the UK Chief Medical Officers on an update to coronavirus symptoms: 18 May 2020 [Internet]. 2020. Available from: https://www.gov.uk/government/news/statement-fromthe-uk-chief-medical-officers-on-an-update-to-coronavirus-symptoms-18-may-2020

8. Caramelo F, Ferreira N, Oliveiros B. Estimation of risk factors for COVID-19 mortality - preliminary results. 2020. doi: https://doi.org/10.1101/2020.02.24.20027268

9. Pareek M, Bangash M, Pareek N, Pan D, Sze S, Minhas J et al. Ethnicity and COVID-19: an urgent public health research priority. 2020;395(10234):1421-22.

10. Pan D, Sze S, Minhas J, Bangash M, Pareek N, Divall P et al. The impact of ethnicity on clinical outcomes in COVID-19: A systematic review. 2020;23:100404.

11. Rimmer A. Covid-19: Disproportionate impact on ethnic minority healthcare workers will be explored by government. 2020;369:m1562.

12. Garg S, Kim L, Whitaker M, O’Halloran A, Cummings C, Holstein R et al. Hospitalization Rates and Characteristics of Patients Hospitalized with Laboratory-Confirmed Coronavirus Disease 2019 - COVID-NET, 14 States, March 130, 2020. MMWR Morbidity and Mortality Weekly Report. 2020;69(15):458-64.

13. Wang L, He W, Yu X, Hu D, Bao M, Liu H et al. Coronavirus disease 2019 in elderly patients: Characteristics and prognostic factors based on 4-week follow-up. J Infect. 2020;80(6):639-645.

14. Armitage R, Nellums L. COVID-19 and the consequences of isolating the elderly. Lancet Public Health. 2020;5(5):e256.

15. Mahase E. Covid-19: death rate is $0.66 \%$ and increases with age, study estimates. 2020; $369: \mathrm{m} 1327$

16. Cohen J, Kupferschmidt K. Countries test tactics in 'war' against COVID-19. 2020; 367(6484):1287-88.

17. Scientific Advisory Group for Emergencies. Consensus view on behavioural and social interventions [Internet]. 2020. Available from:

https://assets.publishing.service.gov.uk/government/uploads/system/uploads/attachment_data/file/873729/06spi-m-o-consensus-view-on-behavioural-and-social-interventions.pdf

18. Peto J, Alwan NA, Godfrey KM, et al. Universal weekly testing as the UK COVID-19 lockdown exit strategy. 2020;395(10234):1420-21.

19. Burki T. Testing for COVID-19. Lancet Respir Med. 2020;8(7):e63-64.

20. Treibel TA, Manisty C, Burton M, et al. COVID-19: PCR screening of asymptomatic health-care workers at London hospital. 2020;395(10237):1608-10.

21. Peto J. Covid-19 mass testing facilities could end the epidemic rapidly. BMJ 2020;368:m1163.

22. Rubin G, Amlot R, Page L, Wessely S. Public perceptions, anxiety, and behaviour change in relation to the swine flu outbreak: cross sectional telephone survey. 2009;339:b2651.

23. Bish A, Michie S. Demographic and attitudinal determinants of protective behaviours during a pandemic: A review. Br J Health Psychol. 2010;15(4):797-824.

24. Dryhurst S, Schneider C, Kerr J, Freeman A, Recchia G, van der Bles A et al. Risk perceptions of COVID-19 around the world. J Risk Res. 2020;1-13.

25. Seale H, Heywood A, Leask J, Sheel M, Thomas S, Durrheim D et al. COVID-19 is rapidly changing: Examining public perceptions and behaviors in response to this evolving pandemic. PLoS One. 2020;15(6):e0235112.

26. Watson J, Whiting P \& Brush JE. Interpreting a covid-19 test result.2020;369:m1808

27. van der Pligt J. Risk Perception and Self-Protective Behavior. Euro Psychol. 1996;1(1):34-43.

28. Scally G, Jacobson B, Abbasi K. The UK's public health response to covid-19. 2020;369: m1932. 


\section{Supplementary Files}

This is a list of supplementary files associated with this preprint. Click to download.

- Additionalfile1.docx

- Additionalfile2.docx

- Additionalfile3.docx 